\title{
Taxonomic study of the planthopper genus Lacusa Stål, I 862 (Hemiptera, Fulgoromorpha, Lophopidae)
}

\author{
Jichun Xing ${ }^{1,3, \dagger}$, Xiangsheng Chen ${ }^{1,2,3, \uparrow}$ \\ I Institute of Entomology, Guizhou University, Guiyang, Guizhou, P. R. China, 5500252 College of Animal \\ Sciences, Guizhou University, Guiyang, Guizhou, P. R. China, 5500253 Special Key Laboratory for Deve- \\ lopment and Utilization of Insect Resources of Guizhou, Guiyang, Guizhou, P. R. China, 550025 \\ † http://zoobank.org/1CD0E0C8-D09A-41EE-B9C0-478889BED58A \\ $\ddagger$ http://zoobank.org/D9953BEB-30E6-464A-86F2-F325EA2E4B7C \\ Corresponding author:Xiangsheng Chen (chenxs3218@163.com)
}

Academic editor: M. Wilson | Received 8 January 2013 | Accepted 15 April 2014 | Published 28 April 2014

http://zoobank.org/38646370-1FED-4DB6-8261-82774C65FCD3

Citation: Xing J, Chen X (2014) Taxonomic study of the planthopper genus Lacusa Stål, 1862 (Hemiptera, Fulgoromorpha, Lophopidae). ZooKeys 405: 139-148. doi: 10.3897/zookeys.405.6981

\begin{abstract}
The planthopper genus Lacusa Stål, 1862 is reviewed. All species are illustrated and male genital characters are provided, and including two new species: L. digitata sp. n. and L. producta sp. n. from Yunnan Province, China. The species L. orientalis Liang, 2000 is removed from this genus based on the frons with median carina and fore femur and tibia flattened but not foliaceous. A key to species is also given. The type specimens of the new species are deposited in the Institute of Entomology, Guizhou University, Guiyang, China (GUGC).
\end{abstract}

\section{Keywords}

Auchenorrhyncha, morphology, taxonomy, distribution, new species

\section{Introduction}

The planthopper genus Lacusa was established by Stål (1862) for a single species Elasmoscelis fuscofasciata Stål, 1854 from India. Later, Atkinson (1886) placed Cixius eminens Walker, 1858 as a junior synonym of Lacusa fuscofasciata (Stål, 1854). Chou \& Huang (see Chou et al. 1985) described a new species Lacusa yunnanensis from China. Liang

Copyright J. Xing, X. Chen. This is an open access article distributed under the terms of the Creative Commons Attribution International License (CC BY 4.0), which permits unrestricted use, distribution, and reproduction in any medium, provided the original author and source are credited. 
(1996) proposed Lacusa yunnanensis Chou \& Huang, 1985 as a junior synonym of Lacusa fuscofasciata (Stål, 1854). Liang (2000) placed Sarebasa Distant, 1909 as a junior subjective synonym of Lacusa, 1862 and proposed the new combination L. celebris (Distant, 1909), and described a new species L. orientalis from Laos, Vietnam and China. Later, Soulier-Perkins (2001) reinstated Sarebasa as a separate genus based on the phylogenetic analysis in Lophopidae.

Here, we follow Soulier-Perkins (2001) in treating Sarebasa as a genus distinct from Lacusa based on the morphological characteristics for these two genera (see Table 1). The species Lacusa orientalis Liang, 2000 indicates that the original figures and description are not belong to the genus Lacusa based on the frons with median carina and fore femur and tibia flattened but not foliaceous, and it may be belong to the genera Sarebasa or Acothrura, and its placement is not treated further here. Consequently, this genus now contains only one species: L. fuscofasciata.

In this paper, two new species Lacusa digitata sp. n. and Lacusa producta sp. n. are described and illustrated from Yunnan Province, China. The type specimens of the new species and other materials examined are deposited in the Institute of Entomology, Guizhou University, Guiyang, China (GUGC). The genus Lacusa now contains 3 species, a key is given to separate all species.

\section{Material and methods}

Specimens were collected by sweeping net. Dry specimens were used for the description and illustration. External morphology was observed under a stereoscopic microscope and characters were measured with an ocular micrometer. Color pictures for adult habitus were obtained by KEYENCE VHX-1000 system. The genital segments of the examined specimens were macerated in $10 \% \mathrm{NaOH}$ and drawn from preparations in glycerin jelly using a Leica MZ 12.5 stereomicroscope. Illustrations were scanned with Canon CanoScan LiDE 200 and imported into Adobe Photoshop CS8 for labeling and plate composition. Morphological terminology follows Liang (2000).

\section{Taxonomy}

\section{Lacusa Stål}

http://species-id.net/wiki/Lacusa

Lacusa Stål, 1862: 309; Atkinson 1886: 42; Distant 1906: 323; Muir 1930: 478; Chou et al. 1985: 125; Liang 2000: 283.

Type species. Elasmoscelis fuscofasciata Stål, 1854

Description. Body length (from apex of vertex to tip of forewings) less than $10 \mathrm{~mm}$, size medium. Head short, approximately trapezoidal, ratio width of vertex from base to 
length in middle line 1.6, narrower than pronotum; vertex broader than long, anterior margin straight in dorsal view and not produced anteriorly beyond proximal margin of eyes, lateral margins with carinate, with an obsolete median longitudinal carina. Frons with lateral carinae, and with sublateral carinae fused apically, and without median carina. Rostrum extending to meso-trochanter, with ratio subapical to apical segment 2.0. Pronotum slightly longer than vertex, anterior margin roundly produced, posterior margin approximately straight, tricarinate on disc, lateral areas curved down. Mesonotum broad, with tricarinate on disc. Forewings broadly round at apex, outer and inner margins nearly parallel, precostal area with many oblique transverse parallel crossveins; hindwings narrower than forewings. Legs moderately long, fore femora and tibiae foliaceous. Hind tibiae with 3 lateral spines and 3-4 rows with more than 70 small spines apically, apical spines of first hind tarsal segment separated by a pad of microsetae.

Head pale luteous, suffused with piceous brown. Eyes black brown. Frons brown and anteclypeus piceous brown. Antennae black brown. Rostrum yellowish brown. Forewings semiopaque, with three broad fuscous transverse band and irregularly piceous spots; hindwings semihyaline. Fore and middle legs blackish brown; hind legs luteous, pad yellowish. Abdomen piceous brown.

Male genitalia. Pygofer short, upper $1 / 3$ very narrow in lateral view, without appendage. Anal tube longer than pygofer, apex forked in caudal view. Genital styles short to long, dorsolateral with a small hook or a finger-like process near posterior margin. Aedeagus with 2 dorsally directed, spinose processes, dorsally directed at medioventral margin; near base of aedeagus on dorsal side or mediolateral of aedeagus with 2 spinose processes or not; base of aedeagus on dorsal side with 1 spinose process or not, and each base laterally of aedeagus with 1 processes or not.

Diagnosis. The genus Lacusa resembles Pitambara Distant, 1906 and Sarebasa Distant, 1909 in having the vertex not produced anteriorly beyond proximal margin of eyes, apical spines of first hind tarsal segment separated by a pad of microsetae, and frontal disc not longitudinally deeply concave, but differs from these genera by the characters noted in Table 1.

Distribution. China, India, Nepal, Burma, Thailand.

Table I. Differences among Lacusa with Pitambara and Sarebasa.

\begin{tabular}{c|c|c|c}
\hline & Lacusa & Pitambara & Sarebasa \\
\hline $\begin{array}{c}\text { 1.Body length (from } \\
\text { apex of vertex to tip of } \\
\text { forewings, male) }\end{array}$ & Less than $10 \mathrm{~mm}$ & Less than $10 \mathrm{~mm}$ & More than $10 \mathrm{~mm}$ \\
\hline 2.Length of vertex & Broader than long & Longer than broad & Broader than long \\
\hline 3.Midian carina on the frons & Absent & Present & Present even if rudimentary \\
\hline $\begin{array}{c}\text { 4.Median anterior margin of } \\
\text { pronotum }\end{array}$ & Regularly rounded & Anteriorly protuberant & Regularly rounded \\
\hline 5.Fore femur and tibia & Foliaceous & $\begin{array}{c}\text { Flattened but not } \\
\text { foliaceous }\end{array}$ & $\begin{array}{c}\text { Relatively elongate, but not } \\
\text { foliaceously dilated }\end{array}$ \\
\hline $\begin{array}{c}\text { 6.Hind tibiae with lateral } \\
\text { spines (number) }\end{array}$ & 3 & 2 & 3 \\
\hline
\end{tabular}




\section{Key to species (male) of Lacusa from China}

1 Aedeagus stout, its base with 1 spinose process on dorsal side and base laterally

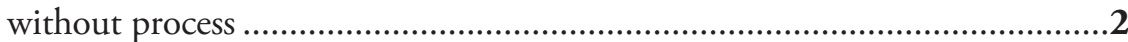

- $\quad$ Aedeagus long and curved in the middle, its base without spinose process on dorsal side and each base laterally with 1 process................... L. fuscofasciata

2 Mediolateral of aedeagus with 2 long spinose processes.... L. producta sp. $\mathbf{n}$.

- $\quad$ Near base of aedeagus on dorsal side with 2 short spinose processes

L. digitata sp. $\mathrm{n}$.

\section{Lacusa fuscofasciata (Stål, 1854)}

http://species-id.net/wiki/Lacusa_fuscofasciata

Figs $1-10$

Elasmoscelis fuscofasciata Stål, 1854: 248.

Cixius eminens Walker, 1858: 42 (synonymized by Atkinson 1886: 42).

Lacusa fuscofasciata (Stål, 1854), comb. n. by Stål, 1862: 309; Atkinson 1886: 42; Distant 1906: 324, Fig. 159; Melichar 1915: 355; Liang 2000: 287, Figs 10, 18-22.

Lacusa yunnanensis Chou \& Huang (in Chou et al.) 1985: 128, 137-138, Fig. 119 (synonymized by Liang 1996: 147).

Material examined. $1 \hat{\partial}$, China: Guizhou Province, Jiangkou County, Fanjingshan National Natural Reserve, 24 September 2011, coll. Weibin Zheng (GUGC); 26 ${ }^{\lambda} 14$ 14우, China: Guizhou Province, Wangmo County, 19 August 2012, coll. Zhimin Chang, Wei-

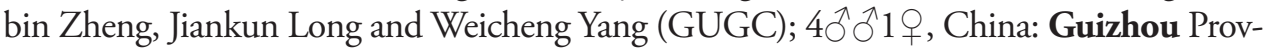
ince, Ceheng County, 25 August 2012, coll. Zhimin Chang, Weibin Zheng and Jiankun Long (GUGC); $2 \widehat{ } \partial^{\lambda}$, China: Guizhou Province, Luodian County, 16 May 2013, coll.

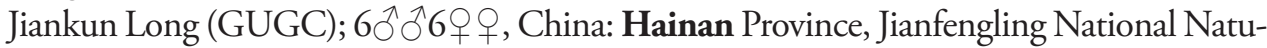
ral Reserve, 9 April 2013, coll. Jiankun Long, Jichun Xing and Yubo Zhang (GUGC); 1 \%, China: Yunnan Province, Ruili City, Nongdao, 15 July 2013, coll. Haiyan Sun (GUGC).

Distribution. China (Yunnan, Guizhou, Guangdong, Hainan), India, Nepal, Burma, Thailand.

Note. Chou \& Huang (in Chou et al. 1985) described a new species L. yunnanensis from Menglun, Xishuangbanna, Yunnan Province, China, based on one female specimen, and they noted that $L$. yunnanensis was closely related to $L$. fuscofasciata, but that it could be distinguished from it by the fuscous transverse band near outer margin on forewing branched and the fuscous meso- and metathorax. Later, Liang (1996) proposed L. yunnanensis as a junior synonym of L. fuscofasciata based on examination of specimens from Yunnan, Guizhou, Guangdong and Hainan Provinces in China.

Body length (from apex of vertex to tip of forewings) of male specimen from Guizhou and Hainan Provinces, relatively small about $6.9 \mathrm{~mm}$, but male specimen from Yunnan Province relatively larger about $8.0 \mathrm{~mm}$. 

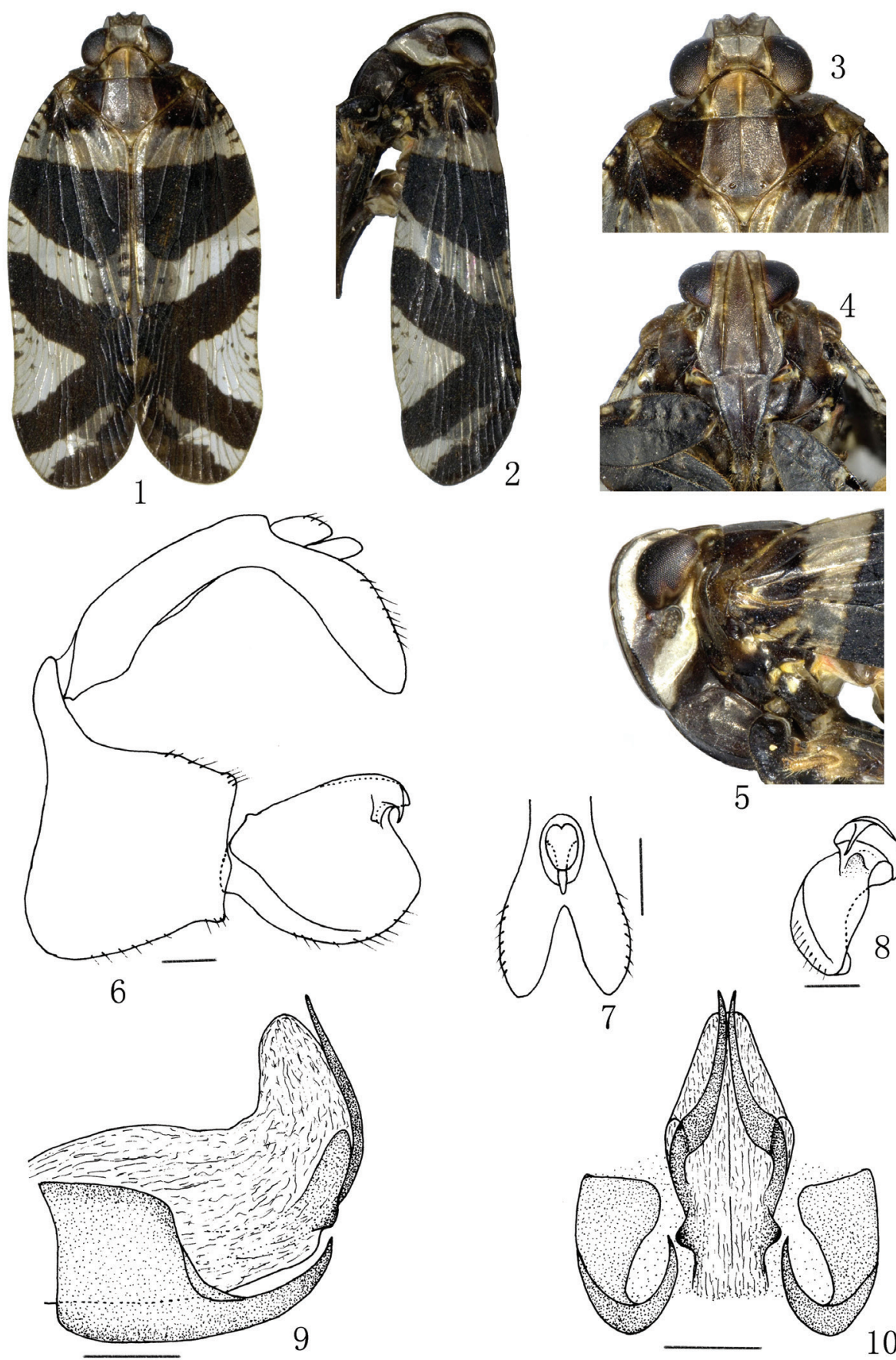

5
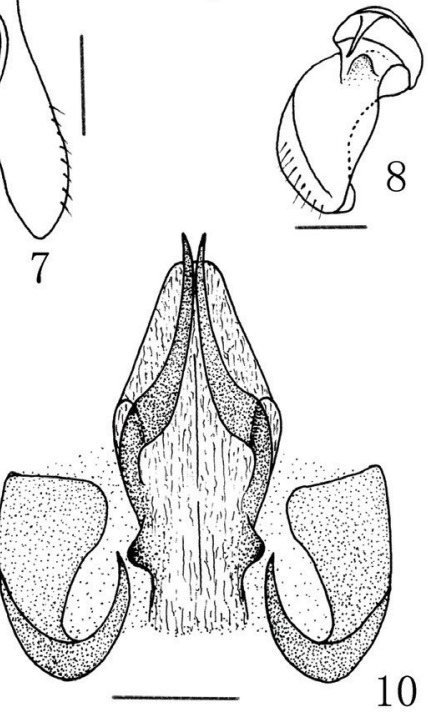

Figures I-10. Lacusa fuscofasciata (Stål, 1854). I Male habitus, dorsal view 2 Male habitus, lateral view 3 Male, head and thorax, dorsal view 4 Male, frons and clypeus 5 Male, head and thorax, lateral view 6 Male genitalia, lateral view 7 Apex of anal tube, caudal view 8 Left genital style, caudal view 9 Aedeagus, lateral view 10 Aedeagus, caudal view. Scale bars: $\mathbf{6}-\mathbf{1 0}=0.20 \mathrm{~mm}$. 

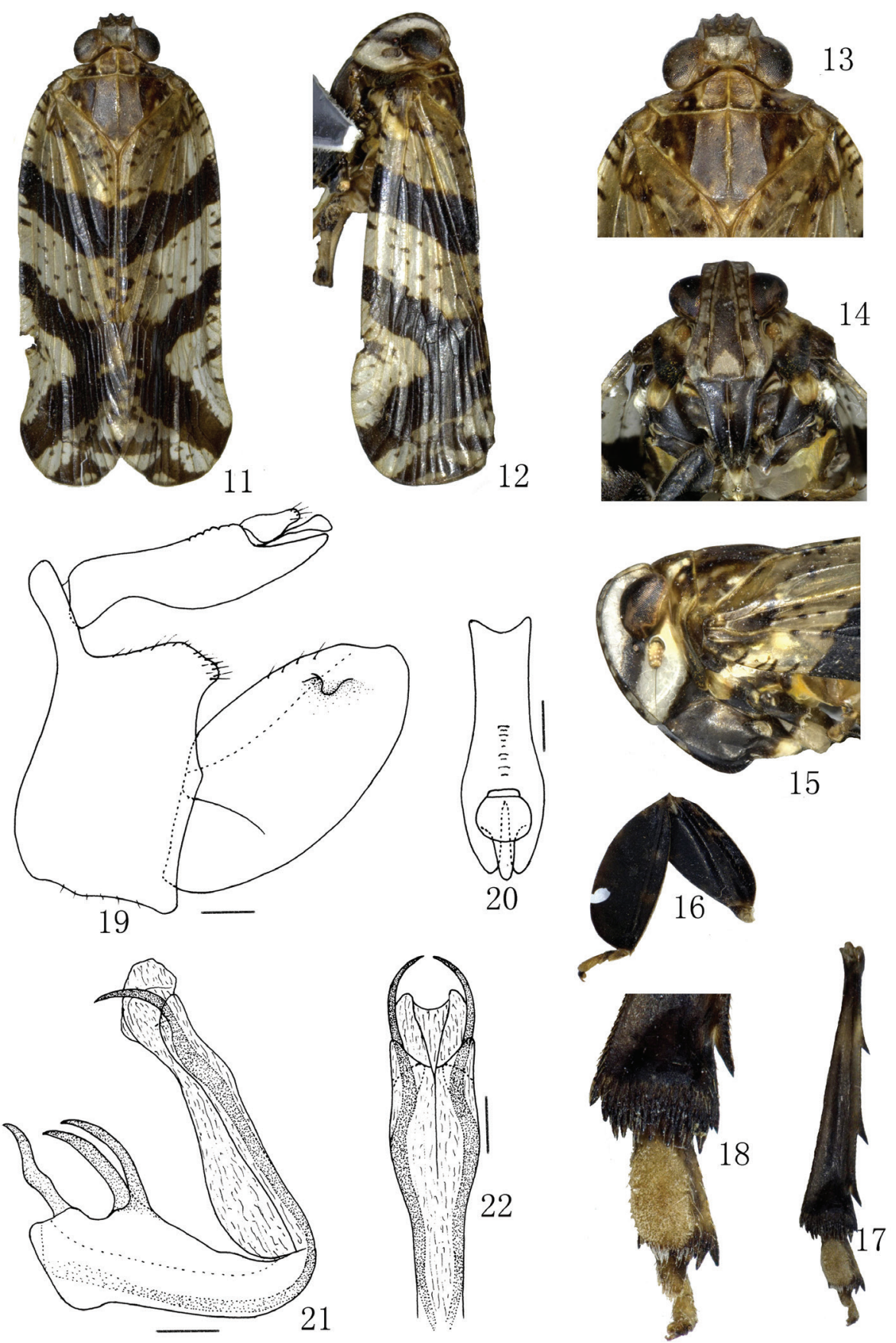

Figures II-22. Lacusa digitata sp. n. I I Male habitus, dorsal view 12 Male habitus, lateral view 13 Male, head and thorax, dorsal view 14 Male, frons and clypeus 15 Male, head and thorax, lateral view 16 Left fore femur and tibia, dorsal view 17 Left hind tibiae and lateral spines, and tarsomere, dorsal view 18 Apex of left hind tibiae and tarsomere, dorsal view 19 Male genitalia, lateral view 20 Anal tube, dorsal view 2 I Aedeagus, lateral view 22 Aedeagus, caudal view. Scale bars: 19-22 $=0.20 \mathrm{~mm}$. 


\section{Lacusa digitata Xing \& Chen, sp. n.}

http://zoobank.org/9CAB07EA-9508-458D-836B-A312AEC90CA1

http://species-id.net/wiki/Lacusa_digitata

Figs $11-22$

Description. Body length (from apex of vertex to tip of forewings): male $8.5-8.7 \mathrm{~mm}(\mathrm{n}=2)$.

Color pattern of anterior dorsum and face as in Figs 11-15. Pronotum and mesonotum yellowish brown. Tegula yellowish. Ocelli red. Apical margin of forewings maculately piceous. External features as in generic description.

Male genitalia. Pygofer short, upper 1/3 very narrow in lateral view, dorsal margin strongly concave (Fig. 19). Anal tube in dorsal view with ratio length to maximum width 3.0 (Fig. 20). Genital styles long, apex approximately round in lateral view, dorsolateral with a finger-like process near posterior margin (Fig. 19). Aedeagus with 2 dorsally directed, spinose processes, dorsally directed at medioventral margin, and exceed the end of aedeagal shaft; near base of aedeagus on dorsal side of aedeagus with 2 short spinose processes; base of aedeagus on dorsal side with 1 short spinose process (Figs 21, 22).

Type material. Holotype: $\widehat{\partial}$, China: Yunnan Province, Ruili City, Mengla County, Moli, 5 June 2011, coll. Jiankun Long (GUGC); paratypes: 10, Yunnan Province, Lianghe County, Mengyang, 27 July 2013, coll. Zhihua Fan (GUGC).

Diagnosis. This species is similar to Lacusa fuscofasciata (Stål, 1854) but can be distinguished by the base of aedeagus on dorsal side with one spinose process, near base of aedeagus on dorsal side with two short spinose processes, the anal tube relatively short, and the genital styles much more long.

Etymology. The species name is derived from the Latin word "digitata", indicating that the genital style dorsolateral with a finger-like process near posterior margin.

\section{Lacusa producta Xing \& Chen, sp. n.}

http://zoobank.org/D770CD3E-2AC6-4C93-9A7D-AF6AEE307EA4

http://species-id.net/wiki/Lacusa_producta

Figs $23-31$

Description. Body length (from apex of vertex to tip of forewings): male 9.2-9.3mm (n=3).

Color pattern of anterior dorsum and face as in Figs 23-27. General appearance as in Lacusa digitata sp. n., but the body much larger.

Male genitalia. Pygofer short, upper 1/3 very narrow in lateral view, dorsal margin strongly concave, posterior margin angle producted near the middle; (Fig. 28). Anal tube in dorsal view with ratio length to maximum width 4.1 (Fig. 29). Genital styles long, apex approximately round in lateral view, dorsolateral with a small hook process near posterior margin (Fig. 28). Aedeagus with 2 dorsally directed, spinose processes, dorsally directed at medioventral margin, and exceed the end of aedeagal shaft; mediolateral of aedeagus with 2 long spinose processes; base of aedeagus on dorsal side with 1 spinose process (Figs 30, 31). 

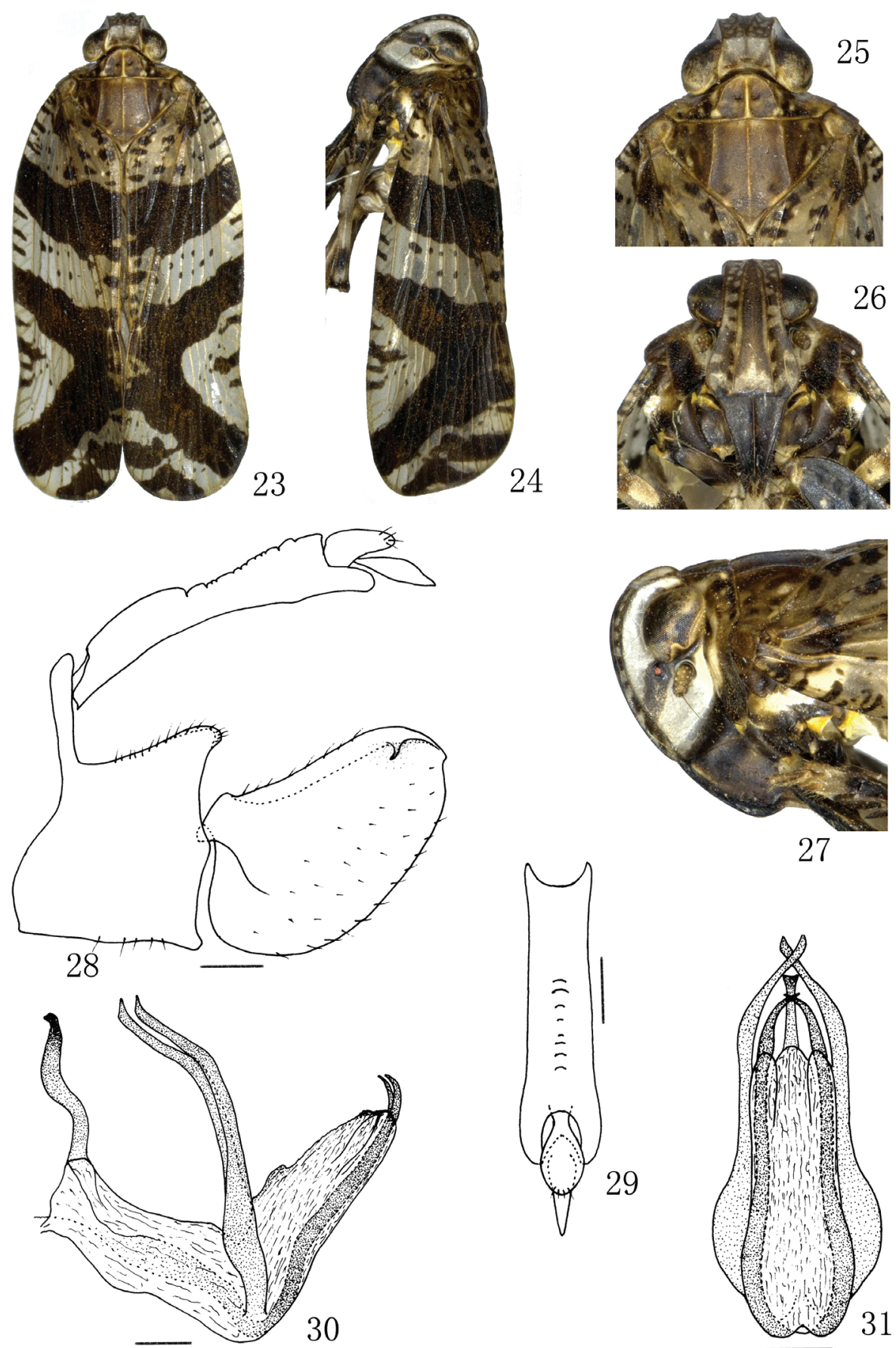

29

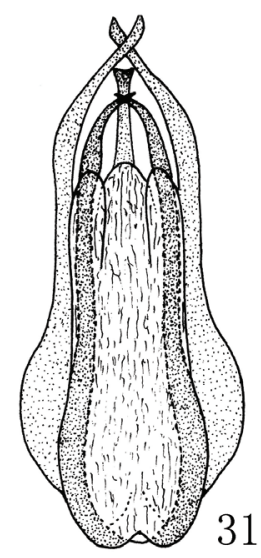

Figures 23-31. Lacusa producta sp. n. 23 Male habitus, dorsal view 24 Male habitus, lateral view 25 Male, head and thorax, dorsal view 26 Male, frons and clypeus 27 Male, head and thorax, lateral view 28 Male genitalia, lateral view 29 Anal tube, dorsal view $\mathbf{3 0}$ Aedeagus, lateral view $\mathbf{3}$ I Aedeagus, caudal view. Scale bars: $\mathbf{2 8 - 3 1}=0.20 \mathrm{~mm}$. 
Type material. Holotype: $\widehat{\partial}$, China: Yunnan Province, Xishuangbanna, Mengla County, Mohan, 25 July 2013, coll. Jichun Xing (GUGC); paratypes: $2 \widehat{\lambda}$, Yunnan Province, Xishuangbanna, Mengla County, Mohan, 25 July 2013, coll. Yuan Liu and Yangyang Liu (GUGC).

Diagnosis. This species is similar to Lacusa digitata sp. $\mathrm{n}$. but can be distinguished by the mediolateral of aedeagus with two long spinose processes, genital style dorsolaterally with a small hook process near posterior margin, the anal tube relatively long.

Etymology. The species name is derived from the Latin word "producta", indicating that the mediolateral of aedeagus with two long spinose processes.

\section{Acknowledgements}

We are grateful to all collectors for collecting specimens. We also thank Prof. Michael Wilson (Department of Biodiversity \& Systematic Biology, National Museum of Wales, Cardiff, UK) and an anonymous referee for reading the manuscript and making some suggestions. This work was supported by the National Natural Science Foundation of China (No.31060290, 31093430) and the International Science and the Program for New Century Excellent Talents in University (NCET-07-0220).

\section{References}

Atkinson ET (1886) Notes on Indian Rhynchota. No. 5. Journal and Proceedings of the Asiatic Society of Bengal 55: 12-83.

Chou I, Lu JS, Huang J, Wang SZ (1985) Economic insect fauna of China. Fasc. 36. Homoptera: Fulgoroidea. Science Press, Beijing, China, 152 pp. [In Chinese with English summary]

Distant WL (1906) The fauna of British India, including Ceylon and Burma. Rhynchota 3 (Heteroptera-Homoptera). Taylor \& Francis, London, 503 pp.

Distant WL (1909) Rhynchota malayana Part II. Records of the Indian Museum 3: 163-181. Liang AP (1996) Taxonomic changes in Chinese Lophopidae with a check list of Chinese species (Homoptera: Fulgoroidea). Pan-Pacific Entomologist 72: 145-151.

Liang AP (2000) Oriental Lophopidae: new taxa and taxonomic changes (Insecta: Hemiptera: Fulgoroidea). Reichenbachia 33: 281-311.

Melichar L (1915) Monographie der Lophopinen. Annales Historico Naturales Mu- sei Nationalis Hungarici 13: 337-384.

Muir FAG (1930) On the classification of the Fulgoroidea. Annals and Magazine of Natural History (Ser.10) 6: 461-478.

Soulier-Perkins A (1998) The Lophopidae (Hemiptera: Fulgoromorpha): description of three new genera and key to the genera of the family. European Journal of Entomology 95: 599-618.

Soulier-Perkins A (2001) The phylogeny of the Lophopidae and the impact of sexual selection and coevolutionary sexual conflict. Cladistics 17: 56-78. doi: 10.1111/j.1096-0031.2001. tb00111.x 
Stål C (1854) Nya Hemiptera. Ofversigt af Kongliga Svenska Vetenskaps-Akademiens Förhandlingar 11: 231-255.

Stål C (1862) Novae vel minus cognitae Homopterorum formae et species. Berliner Entomologische Zeitschrift 6: 303-315. 